\title{
A sliding-window based signal processing method for characterizing clusters in gas-solids high-density CFB reactor
}

\author{
Chengxiu Wang ${ }^{1}$, Mengjie Luo ${ }^{1}$, Xin $\mathrm{Su}^{1}$, Xingying Lan ${ }^{1}$, Zeneng Sun ${ }^{2}$, Jinsen Gao ${ }^{1}$, Mao \\ $\mathrm{Ye}^{3}$, and Jesse $\mathrm{Zhu}^{2}$ \\ ${ }^{1}$ China University of Petroleum Beijing State Key Laboratory of Heavy Oil Processing \\ ${ }^{2}$ The University of Western Ontario \\ ${ }^{3}$ Dalian Institute of Chemical Physics, Chinese Academy of Sciences
}

December 17, 2021

\begin{abstract}
Particle clusters in CFB risers were identified from the instantaneous solids holdup signals by a new sliding-window based signal processing method. By shifting the sliding time window and calculating the mean and the standard deviation within it, a non-linear threshold curve for identifying the clusters was derived instead of the conventional constant threshold. The optimal sliding window size was determined as $\mathrm{Wb}=1024$ data points based on the bisection method on the entire piece of signals. Using the proposed method, a more realistic characterization of the clusters in both the HDCFB and LDCFB was obtained by considering the bulk fluctuation of the gas-solids flow. The clusters in the HDCFB have higher solids holdup and lower velocity than that in the LDCFB. The HDCFB is also found to have a greater number of loose clusters for better gas-solids contacting and exchanges in the center of the riser.
\end{abstract}

\section{Hosted file}

draft_ofp_riser-20211112.docx available at https ://authorea.com/users/301599/articles/549857a-sliding-window-based-signal-processing-method-for-characterizing-clusters-in-gassolids-high-density-cfb-reactor 